\title{
Assess the Level of Perception Regarding Instructor Caring Behaviour among Nursing Students at SRM College of Nursing
}

\author{
Abirami P. \\ Ph.D. (N), Professor, Dept. of Obstetrics and Gynaecology Nursing, SRM College of Nursing, \\ Kattankulathur, Tamil Nadu
}

\begin{abstract}
Introduction: Caring is actually fundamental concept in nursing and manifests openness and honesty in the humanitarian area and the core of nursing science. Caring is the heart and soul of nursing, and people expect caring more than any other from nurses. Caring in nursing consist of two key dimensions, namely physical and mental. The psychological caring behaviors results in building confidence the feeling, faith and honesty of nursing: is caring a science.
\end{abstract}

Aim: A study to assess the level of perception regarding instructor caring behavior among nursing students at SRM College of Nursing, SRM Institute of Science and Technology, Kattankulathur.

Methodology: Non experimental descriptive research design was used to assess the level of perception regarding instructor caring behavior among nursing students. The study was conducted at SRM college of nursing, Kattankulathur, Kancheepuram district. 200 students who were studying at SRM college of nursing were selected by Non - probability convenient sampling technique. Research design was descriptive design. The data collection consisted two parts.Part A Demographic variables, Part B The structured questionnaire to assess the level of perception regarding instructor caring behavior among nursing students. It was validated and found to be feasible.

Results and Conclusion: The following conclusions were drawn and the basis of the findings of the study. $121(54.3 \%)$ Students have perceived that their was a moderate level of caring behavior by the instructor, 90 (40.4\%) students have perceived that their was a high level of caring behavior by the instructor.

Keywords: Caring Behaviour,Instructor, Nursing students.

\section{Introduction}

Caring is actually fundamental concept in nursing, and manifests openness and honesty in the humanitarian area and the core of nursing science. ${ }^{1}$ Caring is the heart and soul of nursing, and people expect caring more than any other from nurses. ${ }^{2}$ Caring in nursing consists of two key dimensions, namely physical and mental. The psychosocial caring behaviors result in building confidence, accepting the feelings, faith and honesty. ${ }^{3}$

It is decades since Florence Nightingle' time that scientists have been studying the nature, definition and assessment of nursing: is caring a science? And how can "caring" be taught? ${ }^{4}$

Having perceived the importance of caring in nursing teaching, students can learn professionalism. ${ }^{5}$ A major part of nursing students' courses are taught in hospitals under the supervision of various clinical instructors. ${ }^{6}$ Clinical instructors are the fundamental important agents in programming and acquiring clinical experiences, ${ }^{7}$ because they can also establish the discipline and be a supportive agent for building students' effective communication, students' accountability and effective acquisition of scientific and clinical skill, and reducing their fear and anxiety through providing students with suitable corrective feedback and active presence as a source of reassurance and confidence. ${ }^{8}$

The nursing instructors are responsible for developing nursing curricula and using active learning strategies that will help students to learn caring behavior. ${ }^{9}$ It is obvious that the clinical instructors preparing their students for entering clinical work places must meet the caring behavior. ${ }^{10}$ 
Previous studies showed that caring behavior played an important role in dynamism of instructor-student relationship. $^{11,12}$ In 2006, Wade and Kasper found that when instructors were taken as caring individuals, students also develop their own abilities. According to Wade, five special caring factor were effective in nursing students' perception of instructors caring, including instill confidence through caring, supportive learning climate, appreciation of life meaning, control versus flexibility, and respectful sharing. Based on Watson's theory of care, caring was represented by instructors and perceived by students in order to facilitate the acquisition of professional role, caring attitude, clinical selfconfidence, clinical competency and interpersonal caring interactions in students. ${ }^{13}$ Students learn caring through copying instructors' caring behaviors and experiencing caring with their interactions with instructors and other students.

Moreover, students perceive the presence or absence of support according to the type of contacts feedbacks receiving from their instructors, ${ }^{14}$ to student instructors are individuals encouraging them, helping them to express their feelings, and inspiring them the selfconfidence. ${ }^{15}$ Furthermore, students make the flexibility. Kindness, respectfulness and being encouraging as the characteristic of instructor caring behaviors and they take the humiliation, rudeness, negligence and unavailability as instructor non-caring behavior. The instructor noncaring behavior arouses negative feelings in students, including ostracism, dissuasion, lost confidence, hopelessness, emotional turmoil ${ }^{16}$ and increasing anxiety. ${ }^{17}$ Wangletzkus believed that instructors could influence student learning positively and reduce the anxiety and loss interest in learning through increasing self-confidence, improving interpersonal relationships and help better understanding of role of education and becoming interested in education and therefore, students felts more freely to ask for help from instructors. ${ }^{\mathbf{1 8}}$

Moreover, students took instructors' behavior "awkward and hostile", 19 as the instructors did not only reduce students' stress in the clinical environment but also increasing students stress and anxiety ${ }^{20,21}$ Furthermore, inappropriate reaction to students' errors and unfair assessment made nursing students disappointed and unmotivated. ${ }^{22}$ The absence of interest and motivation in student are of important barriers to the clinical education. ${ }^{23}$

Since caring behavior of clinical teacher is one of the most important and influential factors in the process of clinical instruction, so far has not been paid enough attention. In other words, there has been so little research couldn't present the clear image of caring dimension, therefore, the present study was conducted to determine the level of perception regarding instructor caring among nursing students' at SRM College of Nursing.

\section{Methodology}

A non experimental descriptive research design was used to assess the level of perception regarding instructor caring behavior among nursing students. The study was conducted at SRM College of nursing, Kattankulathur, Kancheepuram district. 200 students were studying in the SRM College of nursing were selected by Nonprobability convenient sampling technique inclusion and exclusion criteria

Tools for Data Collection: The tool was consists of two sections. Section A deals with demographic details of students such as age, sex, year of study, prior education, religion, siblings, family, father or mother occupation, monthly family income, socio economic class and residence and section $B$ consist of 30 questions to assess the level of perception regarding instructor caring behavior among nursing students. Each question was given 6 options.

a. Strongly disagree -1

b. Moderately disagree - 2

c. Slightly disagree -3

d. Slightly agree -4

e. Moderately agree- 5

f. Strongly agree -6

\section{Scoring Interpretation:}

a. 1 to 60 - low level of instructor caring behavior (1 to $33 \%$ )

b. 61 to 120 - moderate level of instructor caring behavior (34 to $67 \%$ )

121 to 180 - high level of instructor caring behavior (68 to $100 \%$ )

Ethical Consideration: Formal approval was obtained from the institution review board and institutional ethical committee of SRM Institute of Science and Technology, Kattankulathur, Kancheepuram district, Tamil Nadu, India. 
Statistical Analysis: Descriptive and inferential statistics were used to assess and to associate the level of perception regarding instructor caring behavior among nursing students.

\section{Results}

Table 1: Frequency and percentage distribution of level of perception regarding instructor caring behavior among nursing students. $\mathbf{N}=\mathbf{2 0 0}$

\begin{tabular}{|c|l|c|c|}
\hline S.No. & $\begin{array}{l}\text { Level of perception } \\
\text { regarding Instructor } \\
\text { caring behavior }\end{array}$ & $\begin{array}{c}\text { No. of } \\
\text { Students }\end{array}$ & Percentage \\
\hline 1 & Low & 12 & $5.4 \%$ \\
\hline 2 & Moderate & 121 & $54.3 \%$ \\
\hline 3 & High & 90 & $40.4 \%$ \\
\hline
\end{tabular}

\section{Discussion}

The study finding was the among 200 selected samples regarding assess the level of perception regarding instructor caring behavior among nursing students at SRM college of nursing, SRM Institute of Science and Technology, Kattankulathur.

The first objective was to assess the level of perception regarding instructor caring behavior among nursing students: The finding were 12(5.4\%) student have perceived that their was a low level of caring behavior by the instructor, 121(54.3\%) student have perceived that their was a moderate level of caring behavior by the instructor, 90(40.4\%) student have perceived that their was a high level of caring behavior by the instructor regarding instructor caring.

The second objective of the study was to associate the perception of instructor caring behavior among nursing students with their demographic variables: Considering the association of the perception of instructor caring behavior among nursing students with their demographic variables, elder and senior had more perception score than others. The level of perception with demographic variables was assessed using chisquare test. The level of perception of instructor caring behavior was associated with the variables such as sex $\left(\mathrm{X}^{2}=0.945 \mathrm{P}-0.623\right)$, and age $\left(\mathrm{X}^{2}=4.379 \mathrm{P}-0.625\right)$, and course $\left(\mathrm{X}^{2}=16.560 \mathrm{P}-0.011^{*}\right)$, and year of study $\left(X^{2}=12.672\right.$ P- $\left.0.049 *\right)$, and religion $\left(X^{2}=8.970 \mathrm{P}-\right.$ $0.175)$, and numbers of siblings $\left(X^{2}=3.998 \mathrm{P}-0.406\right)$, and types of family $\left(\mathrm{X}^{2}=5.551 \mathrm{P}-0.475\right)$, and fathers occupation $\left(\mathrm{X}^{2}=10.738 \mathrm{P}-0.552\right)$, and family monthly income $\left(\mathrm{X}^{2}=3.415 \mathrm{P}-0.970\right)$, and socio economic class $\left(\mathrm{X}^{2}=17.808 \mathrm{P}-0.023^{*}\right)$ and residence $\left(\mathrm{X}^{2}=7.391 \mathrm{P}-\right.$ $0.117)$. Hence the hypothesis stated 'there is significant association of level of perception regarding instructor caring behavior among nursing students with their demographic variables are " course, year of study and socio economic status" and no significant association of level of perception regarding instructor caring behavior nursing students with their demographic variables are “ course, year of study, and socio economic status.

Similar study conducted by Wade and kasperin Pennsylvania on 88 nursing student of the last year and 43 nursing student of the third year with the mean age of 23 (4.79) years and female percentage of $92.2 \%$ showed the total mean of 224.75(49.6) for the clinical instructor caring behaviors. The above total mean was higher and wade's study did not provide results for each dimension. Similar study done by Wang Letzkus in California on 138 nursing student of the third year and 101 nursing students of the last year from five academic semesters with the mean age of 24.51 (4.72) years and female percentage of $91.2 \%$ from three large nursing schools revealed the total mean for the clinical instructor caring behavior as $4.96(0.69)$. The maximum and minimum mean was respectively related to instill confidence through caring and appreciation of life meanings 24

\section{Conclusion}

The present study assed the level of perception of instructor caring behavior among the nursing students in SRM college of nursing, Kattankulathur. The results of the study concluded that the maximum students were $121(54.3 \%)$ perceived that there was a moderate level of caring behavior by the instructor 90 (40.4\%) student have perceived that there was a high level of caring behavior by the instructor 12(5.4\%) student have perceived that there was a low level of caring behavior by the instructor. Hence the perception of instructor caring behavior among the nursing students can be enhanced through compassion, competence, conscience, confidence and commitment among instructors working in the clinical area.

Acknowledgement: The author acknowledges Dr. C.kanniammal Dean, SRM College of Nursing for constant guidance, We would like to thank study participants for their constant support.

Conflict of Interest: No conflict of interest. In addition, this study was not funded 
Statement of Human and Animal Rights: All procedures followed were in accordance with the ethical standards of the responsible committee on human experimentation (institutional and national) and with the Helsinki Declaration of 1975, as revised in 2008

Statement of Informed Consent: Informed consent was obtained from all the study participants for being included in the study.

\section{Reference}

1. Watson J. Assessing and measuring caring in nursing and health science. New York: Springer Publishin; 2002.

2. Nelson N. Beginning nursing students' perceptions of the effective characteristics and caring behaviors of their clilnical instructor [dissertation]. New York: Capella; 2011.

3. Woodward VM. Professional caring: a contradiction in terms? Journal of Advanced Nursing. 1997;26(5):999-1004.

4. Cook PR, Cullen JA. Caring as an imperative for nursing education. Nursing Education Perspectives . 2003; 24 (4):192-7.

5. Wade GH, Kasper N. Nursing students' perceptions of instructor caring: an instrument based on Watson's theory of transpersonal caring. Journal of Nursing Education . 2006; 45 (5):162-8.

6. Najafipour S, Raoofi R, Abdi MH, Mosalanejad L. The nursing students' viewpoints on influential clinical instructor in Jahrom University of Medical Sciences. ournal of Jahrom University of Medical Sciences . 2011;9:39-46. (Persian)

7. Pazandeh F, Abedian K, Jan-Nesari S, Alavi-Majd H. Opinions of nursing and midwifery students regarding an effective clinical tutor at Medical Universities in Tehran. ournal of Shahid Beheshti school of Nursing \& midwifery. 2006;55(16):4654. (Persian)

8. Alavi M, Abedi H. Nursing students' experiences and perceptions of effective instructor in clinical education. Iranian Journal of Medical Education. 2008;7(2):325-334. (Persian)

9. Karaöz S. Turkish nursing students' perception of caring. Nurse Education Today . 2005; 25 (1):3140.

10. Wafaa GA. Caring and effective teaching behavior of clinical nursing instructors in clinical area as perceived by their students. Journal of Education and Practice . 2012; 3 (7):15-26.

11. Wang Letzkus M. Nursing students' perceptions of a caring clinical instructor [dissertation]. California: Pepperdine; 2005.

12. Clawson Roe D. The relationship between prelicensure baccalaureate nursing students' stress and their perceptions of clinical nurse educator caring [dissertation]. New Orleans: Louisiana; 2009.

13. Beck C. Caring within nursing education: a metasynthesis. Journal of Nursing Education . 2001; 40 (3):101-9.

14. Salmani N, Amirian H. Comparison between nursing students and trainers viewpoints about clinical educator environment in Islamic Azad university of Yazd. Strides in Development of Medical Education. 2006;1(3):11-8. (Persian)

15. Nahas VL, Nour V, Al-Nobani M. Jordanian undergraduate nursing students' perceptions of effective clinical teachers. Nurse Educ Today . 1999; 19 (8):639-48.

16. Hanson L, Smith M. Nursing students' perspectives: experiences of caring and not-so-caring interactions with faculty. Journal of Nursing Education . 1996; 35 (3):105-12.

17. Cook L. Inviting teaching behaviors of clinical faculty and nursing students' anxiety. Journal of Nursing Education . 2005; 44 (4):156-62.

18. Heydari M, Shahbazi S, Sheykhi RA, Heydari K. Nursing students' viewpoints about Problems of clinical education. Iranian Journal of Health \& Care. 2011;1(13):18-23. (Persian)

19. Alavi M, Irajpour AR, Nasiri A, Abedi HA. Barriers to clinical education: student nurses' experiences. Scientific Quarterly of Birjand Nursing and Midwifery Faculty. 2009;1-4(6):5-11. (Persian)

20. Delaram M, Raeisi Z, Alidousti M. Strengths and weaknesses of clinical education from the viewpoints of nursing and midwifery students in Shahrekord University of Medical Sciences. Qom University of Medical Sciences Journal. 2012;6(2):76-81. (Persian)

21. Abedini S, Agha Mullahei $\mathrm{T}$, Jomehzadeh A, Kamjo A. Clinical education problems from the viewpoint of nursing and midwifery students of Hormozgan University of Medical Sciences. Hormozgan Medical Journal. 2009;12(4):249-53. (Persian) 
22. Salehian M, Armat MR.. Qualitative study of nursing student experiences in clinical education. Journal of North Khorasan University of Medical Sciences. 2009; 23(1):57-63. (Persian)

23. Rahimi A, Ahmadi F. The obstacles and improving strategies of clinical education from the viewpoints of clinical instructors in Tehran's Nursing
Schools. Iranian Journal of Medical Education. 2006;5(2):77-84.(Persian)

24. Vahid Zamanzadeh, Masoumeh Shohani,Tina Palmeh, Nursing Students' Perception of Instructors' Caring Behaviors in Tabriz University of Medical Sciences, Journal of Caring Sciences, 2015 Mar; 4(1): 55-62. 